\title{
ENSINO TECNÓLOGO JURÍDICO E O AGRAVAMENTO DA CRISE DO ENSINO JURÍDICO
}

\section{LEGAL TECHNOLOGIST EDUCATION AND THE AGGRESSION OF THE CRISIS OF LEGAL EDUCATION}

\author{
Karyna Batista Sposato ${ }^{1}$ \\ João Víctor Pinto Santana ${ }^{2}$
}

Data de recebimento: $27 / 03 / 2018$

Data de Aprovação: 04/08/2018

\section{RESUMO}

O presente trabalho, partindo da premissa de que a problemática relacionada à crise do ensino jurídico não é recente, busca discutir a implantação de curso tecnólogo jurídico como reflexo de um agravamento da crise do ensino jurídico brasileiro. Para tanto, sustenta a necessidade de ser reforçada a crítica à dogmática jurídica, com base na compreensão do senso comum teórico dos juristas, com o escopo de potencializar a construção do pensamento crítico do direito. Utilizando-se de pesquisa bibliográfica qualitativa, procurou-se contribuir para uma análise crítica do ensino jurídico, problematizando seus principais impasses e riscos para um verdadeiro colapso. Por fim, propõe-se uma reflexão sobre os desafios a serem enfrentados diante da crise do ensino jurídico brasileiro.

1 Professora Adjunta do Departamento de Direito da Universidade Federal de Sergipe (UFS). Doutora em Direito pela Universidade Federal da Bahia (UFBA). Mestre em Direito pela Universidade de São Paulo (USP).

Email: karyna.sposato@gmail.com.

${ }^{2}$ Mestrando em Direito pela Universidade Federal de Sergipe - UFS. Bolsista da Fundação de Apoio à Pesquisa e à Inovação Tecnológica do Estado de Sergipe - FAPITEC/SE. Advogado. Pós-graduado em Direito Penal Econômico pela Universidade de Coimbra (Portugal).

Email: j.victorsantana@hotmail.com 


\title{
PALAVRAS-CHAVE
}

Tecnólogo jurídico. Impossibilidade. Agravamento da crise do ensino jurídico.

\begin{abstract}
The present study, based on the premise that the problem related to the legal education crisis is not recent, seeks to discuss the implementation of a legal technologist course as a reflection of a worsening of the Brazilian legal education crisis. In order to do so, it maintains the need to reinforce the critique of legal dogmatics, based on the understanding of the theoretical common sense of jurists, with the scope of potentializing the construction of critical thinking in law. Using a qualitative bibliographical research, it was tried to contribute to a critical analysis of the legal education, problematizing its main impasses and risks for a true collapse. Finally, it is proposed a reflection on the challenges to be faced in the face of the Brazilian legal education crisis.
\end{abstract}

\section{KEYWORDS}

Legal technologist. Impossibility. Worsening of the legal education crisis. 


\section{INTRODUÇÃO}

Este trabalho procura analisar a crise do ensino jurídico no Brasil, a partir de um olhar dirigido à complexidade de elementos que estão presentes na formação do profissional da área jurídica.

Entende-se por crise do ensino jurídico, o fenômeno complexo que envolve diversos fatores intrínsecos ao processo de aprendizagem, como a relação entre professor e aluno, assim como fatores diretamente extrínsecos, a saber: políticas públicas e decisões institucionais que direcionam a abordagem, a fiscalização e os métodos ${ }^{3}$ de ensino jurídico no país.

Há que se destacar que a crise do ensino jurídico é uma questão estrutural, imbricada no sistema de formação de categorias profissionais a ocuparem espaços e lugares institucionais pré-definidos. ${ }^{4}$

Sendo assim, o presente estudo sustenta a necessidade de ser reforçada a crítica à dogmática jurídica ${ }^{5}$, com base na "caracterização e explicitação do senso comum teórico dos juristas" (WARAT, 2004d, p. 29), com o escopo de potencializar a construção do pensamento crítico do direito.

A crítica de Warat (2004d, 2004b; 2004c; 2004) ainda continua atual e é imprescindível para a análise de alterações contemporâneas no ensino jurídico, na medida em que o senso comum teóricos dos juristas, representa o "conhecimento que se encontra na base de todos os discursos científicos e epistemológicos do Direito" (STRECK, 2013, p. 12).

\footnotetext{
${ }^{3}$ Predomina, na cultura jurídica, o método de transmissão de conteúdo expositivo. Entretanto, é importante destacar que já existem, no Brasil, algumas experiências acerca de outros métodos de ensino, a exemplo da metodologia do Aprendizado Centrado em Problemas (Problem-Based Learning - PBL). Para compreender essa abordagem de ensino, e a consequente aplicabilidade no âmbito jurídico, remete-se à reflexão de Horácio Wanderlei Rodrigues (2010).
}

\footnotetext{
${ }^{4}$ Segundo os dados do censo do Poder Judiciário, realizado pelo Conselho Nacional de Justiça (2014), cerca de 60,8\% (sessenta vírgula oito por cento) dos magistrados da justiça federal concluíram em Instituições de Ensino Públicas, enquanto que $39,2 \%$ (trinta e nove vírgula dois por cento) dos magistrados da justiça federal concluíram a graduação em Direito em Instituição de Ensino Privada.

${ }^{5}$ Sobre a reprodução do paradigma dogmático, qual seja: o positivismo jurídico, é pertinente a análise de Samara Tavares Agapto das Neves (2010). Este debate é fundamental, pois "[...] tradicionalmente, o ensino do Direito sempre deu um peso maior às disciplinas dogmáticas e, quando propôs a introdução de disciplinas zetéticas, o fez sem maior preocupação de articulação com a dogmática, muitas vezes em uma clara hierarquização de saberes nos quais os conteúdos dogmáticos eram priorizados." (ALMEIDA; CAMARGO; SOUZA, 2013, p. 20).
} 
Nesta direção, cabe indagar se a adoção do curso tecnólogo jurídico representa um elemento de reforço ou desconstrução frente à banalização do curso de graduação em Direito e da crise do ensino jurídico. O modelo codificador do ensino estaria sendo absorvido pela demanda do ensino tecnólogo e, assim, a graduação em Direito passaria a ter um ensino crítico-reflexivo? O ensino de curso tecnólogo jurídico seria o remédio ou o veneno para a crise do ensino jurídico no Brasil?

Assim, num período em que "[...] a crise do direito aflora mais e mais, e em tempos de ensino jurídico estandardizado, com publicações simplificadas e simplificadoras pululando em rodoviárias, supermercados e aeroportos" (STRECK, 2013, p. 191), justifica-se o presente artigo pelo fato de fomentar um importante debate - tanto para a comunidade jurídica quanto para a sociedade civil - sobre o ensino jurídico atual.

A preocupação waratiana ${ }^{6}$ com o ensino do Direito foi nitidamente reconhecida, tanto pela pretensão de aprofundamento da criticidade quanto pela busca pela cientificidade e delimitação da epistemologia e empirismo, na ciência jurídica (WARAT, 2004), motivo pelo qual torna-se essencial compreender quais os desafios a serem enfrentados diante da crise do ensino jurídico brasileiro, adotando-se como premissa o entendimento de que "[...] el caminho de las soluciones es bastante complejo; no pueden darse fórmulas invariables ni recetas milagrosas para la resolución de las diversas situaciones que la relación enseñanza aprendizaje va produciendo dia a dia"7 (WARAT, 2004c, p. 361).

Em busca de tais respostas, almeja-se também delinear possíveis alternativas para amenizar os impactos de um declínio do ensino jurídico e, consequentemente, evitar a banalização do papel do profissional de direito e do saber jurídico.

\footnotetext{
${ }^{6}$ Em 1974, Luis Alberto Warat elaborou um curso sobre a metodologia do ensino jurídico, que fomentou o surgimento do trabalho intitulado: "Notas para uma transformación de la enseñanza jurídica". (WARAT, 2004c, p. 361). Nesse curso, diversos aspectos foram discutidos, dentre eles, destaca-se: "a) personalidade del professor y sus formas de comunicación; b) objetivos de la ensenañanza del Derecho; c) formas de evaluación; d) contenidos a trasmitir" (WARAT, 2004c, p. 361). Alguns destes aspectos serão contextualizados no decorrer do presente artigo.

${ }^{7}$ Tradução livre: "O caminho das soluções é muito complexo, não se podem dar fórmulas invariáveis nem receitas milagrosas para a resolução das diversas situações que a relação ensino-aprendizagem produz no dia-a-dia. (WARAT, 2004c, p. 361).
} 


\section{ENSINO JURÍDICO NO BRASIL: BREVE HISTÓRICO}

Durante muito tempo, o Brasil não possuiu ensino jurídico, visto que “[...] os cursos superiores propriamente ditos começaram a ser instalados no Brasil a partir de 1808, com a chegada de D. João VI" (SAVIANI, 2010, p. 4). A independência acadêmico-científica somente ocorreu em 1827, quando surgiram os primeiros cursos jurídicos no Brasil (SILVA, 2001, p. 308; SAVIANI, 2010, p.4), destinados aos interesses do setor economicamente dominante. (NEVES, 2010, p.78; PESSOA, 2013, p. 25-27).

Salienta-se que a referida realidade não se verificou somente no âmbito acadêmico brasileiro, pois a intectualização da elite era um fenômeno presente em diversos países, como bem destacou Umberto Eco (1998, p. XIII).

Nesse contexto, no Brasil, o título superior, mais especificamente, a titulação jurídica, com o passar dos anos, adquiriu um prestígio social e moral na sociedade, tornando-se, assim, objeto de desejo não somente da classe abastada, mas também das demais estratificações sociais da população brasileira. ${ }^{8}$

Essa busca de outras classes econômicas da sociedade brasileira pela titulação jurídica contribuiu para a expansão do ensino jurídico, o que ocorreu significativamente após 1930. Nesse momento, verificou-se, portanto, o início da democratização do ensino jurídico. Acontece que essa expansão do ensino superior, ocorreu de maneira pouco articulada com os órgãos, instituições e sistemas de ensino, proporcionando uma carência entre reformas educacionais e a realidade social (CHAMON, 2006, p. 39), sendo possível constatar que não houve um acompanhamento do ensino do Direito às mudanças ocorridas na sociedade, inclusive na estrutura social, no decorrer dos anos (NEVES, 2010, p. 78).

Como consequências sociais vantajosas dessa democratização do ensino jurídico pode-se destacar, por exemplo: a possibilidade de mobilidade

\footnotetext{
${ }^{8}$ Tal fenômeno social, qual seja: o prestígio da titulação jurídica, ainda encontra-se espraiado na sociedade brasileira. Na literatura, essa realidade relacionada à nobreza, no período da República, pode ser verificada na obra: Os Bruzundangas, de Lima Barreto, pois, para este mencionado autor, a nobreza era detentora da titulação do ensino superior, principalmente em áreas como Medicina e Direito (BARRETO, 1998).
} 
econômica da sociedade e a difusão de conhecimento. Entretanto, como consequência desvantajosa, nota-se a banalização da crise do ensino jurídico.

\section{CRISE DO ENSINO JURÍDICO: A PREOCUPANTE NATURALIZAÇÃO DO SENSO COMUM TEÓRICO DOS JURISTAS}

O ensino jurídico atual não se adequa à realidade a qual foi proposto, ou seja, o ensino jurídico no Brasil já não cumpre a função social da aprendizagem da ciência jurídica (WARAT, 2004c), pois o que se verifica atualmente é a produtividade acadêmica em padrões industriais ${ }^{9}$ e a valorização da mercantilização/comercialização do ensino, em detrimento da efetividade da aprendizagem.

Trata-se de uma realidade que, sem dúvida nenhuma, coloca em risco a qualidade do ensino jurídico. Nesse sentido, torna-se primordial assimilar que o ensino jurídico instrumentalizado, na realidade prática no dia-a-dia em sala de aula, não está de acordo com os parâmetros determinados pelo Ministério da Educação. ${ }^{10}$

Nessa perspectiva, compreende-se o senso comum teórico dos juristas como um "[...] imaginário que atua como um véu que encobre o pensar crítico dos juristas" (STRECK, 2013, p. 14). Nesse sentido, é buscando desvelar as obviedades que é possível compreender direito. Todo senso comum reproduz uma espécie de falácia realista. $\mathrm{O}$ senso comum compreende mal o direito. $\mathrm{O}$ senso comum obnubila a ciência jurídica. (STRECK, 2013, p. 14).

\footnotetext{
${ }^{9}$ Intitula-se, no presente estudo, "industrialização da atividade acadêmica", a lógica de meta/produtividade que atingiu o ensino superior, com o advento de padrões de avaliação de órgão como a Coordenação de Aperfeiçoamento de Pessoal de Nível Superior - CAPES e as próprias Instituições de Ensino Superior.

${ }^{10} E m$ atenção a esta necessária verificação, tem-se que "[...] a Comissão de Ensino Jurídico do MEC, encarregada do "provão", traçou um perfil ideal, com as seguintes características que se espera do graduando em Direito: a) formação humanística, técnico-jurídica e prática indispensável à adequada compreensão interdisciplinar do fenômeno jurídico e das transformações sociais; b) senso ético profissional, associado à responsabilidade social, com a compreensão da causalidade e finalidade das normas jurídicas e da busca constante da libertação do homem e do aprimoramento da sociedade; c) capacidade de apreensão, transmissão crítica e produção criativa do Direito, aliada ao raciocínio lógico à consciência da necessidade de permanente atualização; d) capacidade para equacionar problemas e buscar soluções harmônicas com as exigências sociais; e) capacidade de desenvolver formas extrajudiciais de prevenção e solução de conflitos individuais e coletivos; f) visão atualizada de mundo e, em particular, consciência dos problemas de seu tempo e de seu espaço." (BOVE, 2006, p.134).
} 
Salienta-se, também, que existem outras variáveis que indicam a crise do sistema de ensino jurídico, além da mercantilização do ensino e da industrialização da produtividade acadêmica já mencionadas, como por exemplo: a) Proliferação das Faculdade do Direito; b) $\mathrm{O}$ fortalecimento de um movimento codificador; c) Utilização de metodologia expositiva para a transmissão do conteúdo.

A proliferação das faculdades de Direito é uma realidade que coloca em risco o ensino jurídico, visto que, na prática, parece não haver um efetivo respeito às reservas de mercado, desrespeitando, assim, a basilar lógica econômica da oferta/demanda, sob o fundamento meramente lucrativo, sem nenhum compromisso pedagógico e/ou social.

Essa proliferação das faculdades dos cursos de Direito pode ser justificável, pelo fato de que, atualmente, o curso superior em Direito é pouco oneroso $^{11}$ às instituições de ensino, pois não há a necessidade de laboratórios (como ocorre na área das ciências médicas, por exemplo), de salas especializadas/individualizadas, nem de recursos de aparelhos tecnológicos de precisão (como ocorre na área das engenharias, por exemplo). No curso de Direito, basicamente, apenas há a necessidade de professor e alguns livros na biblioteca (estas muita das vezes estão desatualizados e/ou não estimulam a mínima reflexão sociojurídica). Diante disso, não restam dúvidas que o ensino jurídico se configura como uma atividade empresarial altamente lucrativa, infelizmente.

No que se refere ao movimento codificador, que reproduz meramente o teor da legislação ${ }^{12}$, observa-se a ausência de reflexão crítico-social e do embate cognitivo crítico do Direito. Nota-se que há uma predileção ao positivismo exacerbado como norteamento para a metodologia de ensino, fomentando-se um ensino jurídico cada vez mais afastado da reflexão contextual sociocultural da norma jurídica. Essa metodologia apenas contribui para a manutenção de em sistema de ensino intei-

\footnotetext{
${ }^{11} \mathrm{~A}$ onerosidade aqui referida é no sentido realmente pecuniário, ou seja, de custo/benefício em relação ao mercado educacional.

${ }^{12}$ Também conhecido como modelo de ensino mecanicista, consiste em ser a famigerada metodologia (se é que se denominar de metodologia do ensino jurídico) de reprodução/repetição da mera literalidade da lei (lei seca). Configura-se como um ensino pautado na mera leitura de artigos da legislação, sem a devida promoção da conscientização e criticidade do aluno (BITTAR, 2013, P. 115).
} 
ramente legalista e dogmático, pois nota-se que:

[...] la elección de los métodos didácticos en las escuelas de derecho descansan basicamente en la creencia de que la metodología del codificador es también una buena técnica educativa. Los docentes se limitan así a glosar a los codificadores sin tomar en cuenta la naturaliza de la inteligencia, el papel de la experiencia en la formación del conocimiento y os mecanismos de transmisión. ${ }^{13}$ (WARAT, 1972, p. 17-18).

Outro fator que contribui para a crise do ensino jurídico é a preponderância da utilização da metodologia expositiva na transmissão do conteúdo, pois:

[...] a adoção desse modelo torna problemática a aprendizagem. O professor preocupa-se em expor a matéria e negligencia a importância do interesse e da atenção do aluno. Seu discurso inclui termos que nem sempre existem na experiência dos alunos. Tantas são as ideias apresentadas que boa parte delas não é retida pelos alunos. Alguns professores falam tão rápido que muitas das ideias apresentadas não são percebidas pelos alunos. Outros falam tão baixo e de forma tão monótona que não conseguem manter a atenção dos alunos. Muitos professores ficam tão entusiasmados com a exposição a ponto de deixar de utilizar qualquer recurso audiovisual. Em suma, as aulas expositivas com frequência caracterizamse pelo monólogo. (GIL 2009, p. 69).

Em relação à esta metodologia aplicada, a problemática do ensino jurídico é potencializada, pois se por um lado a metodologia expositiva não é uma das melhores alternativas para a efetivação da aprendizagem, por outro lado "já se apostou no autodidatismo do aluno, isso se mostra absolutamente obsoleto, do ponto de vista pedagógico, em contextos atuais" (BITTAR, 2013,

13 Tradução livre: "[...] a escolha dos métodos didáticos nas faculdades de direito repousa basicamente na crença de que 0 método de codificação também é uma boa técnica educacional. Os professores limitam-se a encobrir os codificadores sem levar em conta a naturalidade da inteligência, o papel da experiência na formação do conhecimento e os mecanismos de transmissão" (WARAT, 1972, pp. 17-18). 
p. 115). Na metodologia expositiva, não há um estímulo para que o discente consiga participar da construção do conhecimento e superar a problemática jurídica. ${ }^{14}$

Assim, percebe-se a importância da influência que os docentes possuem na desconstrução de um ensino codificador e esquematizado, entretanto, nota-se, infelizmente, que:

[...] nenhum professor de direito aconselha: 'não mencione a norma'. Talvez ajam assim por acreditarem em um conceito abstrato de direito que segue o ponto-de-vista tradicional do racionalismo, do iluminismo e do positivismo. Eles ignoram o silêncio e a abertura da normatividade jurídica e fecham os olhos ao caráter retórico do direito e às condições de sua formação. (SOBOTA, 1991, p. 272-273).

Evidencia-se, portanto, um apego exacerbado à norma. ${ }^{15} \mathrm{~A}$ concepção do sistema fora estruturada dessa forma, por este motivo nota-se a dificuldade de romper com este modelo de formação e atuação profissional. Dentro deste contexto, o discente, após a conclusão da graduação, certamente replica os ensinamentos aprendidos na realidade de sua atuação profissional, tendo em vista que a reflexão crítica passou a ser atribuição das pós-graduações ${ }^{16}$. Assim, evidencia-se que:

[...] o trabalho desenvolvido em cursos de pós-graduação tem

\footnotetext{
${ }^{14}$ Nessa mesma linha de raciocínio, tem-se que "[...] o aluno não é estimulado, imperando nas salas de aula o normativismo, ao velho estilo, fazendo com que a integração professor aluno não exista e, consequentemente, nada se construa. A ausência de discussão de problemas, não fornece ao aluno o instrumental teórico e analítico para uma melhor compreensão do mundo em que vive" (BOVE, 2006, p. 137).

${ }^{15} \mathrm{O}$ modelo nitidamente positivista fracassou tanto pela acriticidade quanto pelo apego ao positivismo. Assim, entende-se que a experiência acadêmica deve ser amparada por uma estrutura curricular que possibilite o fornecimento de conhecimentos não somente técnico-jurídico (BITTAR, 2013, p. 115), mas também críticos e reflexivos, conectados com a realidade social.

${ }^{16}$ Mais especificamente às pós-graduações a nível de mestrado e doutorado (as chamadas pós-graduações stricto sensu), que visam formar, capacitar e especializar os juristas para atuarem como docentes/pesquisadores. Atualmente, é nesse espaço acadêmico que se verifica, também, a possibilidade do contato com a temática relacionada à didática do ensino, área que não é evidenciada durante a graduação de Direito, pois nesta área do conhecimento ainda há a associação de atuação profissional com atuação de docência, entretanto, é fundamental compreender que um bom jurista não necessariamente será um bom docente. Nesse sentido, importante é a observação, fundamentada historicamente, feita por Adélia Pessoa em relação à função que a pós-graduação passou a adotar no ensino jurídico, haja vista que "[...] com a abertura de ensino de $3^{\circ}$ grau a muitas parcelas da população, parece hoje que a manutenção da alta cultura como privilégio de alguns, só é possível através de estudos de pós-graduação" (PESSOA, 2013, p. 57).
} 
um papel importante na continuação da qualidade do ensino jurídico, uma vez que tem a função precípua de formar profissionais para as academias, ou seja, aqueles que lidarão diretamente com o ensino jurídico e com a responsabilidade da educação continuada, rica em valores e princípios na perspectiva de formar cidadãos. (SANCHES; GIMENEZ, 2014, p. 13).

Recentemente houve um fomento à democratização do ensino jurídico, com a implantação de políticas públicas de acesso à educação, por meio de financiamentos e concessão de bolsas de estudo em instituições de ensino particular e, além disso, a ampliação de oferta de vagas em instituições de ensino públicas. ${ }^{17}$ Essa realidade contribuiu para o agravamento da crise do ensino jurídico no Brasil.

Assim, observa-se que foi, e continua sendo, crescente o quantitativo de vagas ${ }^{18}$ em cursos de Direito no Brasil, entretanto, os parâmetros para um ensino jurídico crítico e satisfatório à sociedade ainda não estão presentes. $\mathrm{A}$ comprovação disto é a verificação de um sistema de ensino pautado na codificação e esquematização do Direito, conforme já mencionado, e a crescente mão-de-obra, em sua maioria precária cientificamente, no mercado de trabalho, cada vez mais competitivo e exigente. Outra problemática que indica a crise do ensino jurídico é a o incentivo à democratização do ensino jurídico sem o aprimoramento da devida qualidade pedagógico-científica deste ensino.

Verifica-se, sob este contexto, que atualmente o cenário do ensino jurídico indica uma preocupante naturalização do senso comum teórico dos juristas (WARAT, 2004d), diante da acriticidade do direito e da ausência de reflexão acerca da função social da ciência jurídica, proporcionando um estímulo à concepção de que o jurista resume-se a mero operador do direito.

Um dos fatores que, segundo Lenio Streck (2013), contribui para

\footnotetext{
${ }^{17}$ Conforme já destacado em nota de rodapé alhures, o presente trabalho não pretende analisar o fenômeno da (in)efetividade destas políticas educacionais, pois evita-se, aqui, migrar para uma análise da conjuntura político-social do sistema de ensino.

${ }^{18}$ Refere-se às políticas governamentais, como por exemplo: Programa de Apoio a Planos de Reestruturação e Expansão das Universidades Federais - REUNI, Programa Universidade para Todos - PROUNI e o Financiamento ao Estudante do Ensino Superior - FIES.
} 
essa fragilização do direito é justamente o fato de haver um "ensino jurídico, ainda dominado - ou fundamentalmente tomado - por uma cultura estandardizada". (STRECK, 2013, p. 19). Essa banalização do ensino jurídico, de forma estandardizada, se verifica por meio das doutrinas simplificadas, sem discussão reflexiva.

Nessa toada, em virtude desse cenário, percebe-se atualmente que há a busca por outras alternativas para o ensino jurídico, uma delas, por exemplo: é a implantação do ensino do curso de tecnólogo jurídico.

Sendo assim, almeja-se compreender o porquê da implantação do ensino de curso tecnólogo jurídico ser o agravamento da crise do ensino jurídico, na medida em que pode contribuir para um verdadeiro colapso do sistema de ensino jurídico.

Diante desse cenário, compreende-se que muito provavelmente a crise do ensino jurídico não será solucionada, ou sequer amenizada, enquanto não houver uma reflexão jurídico-social aprofundada com base na crítica do direito, por meio de um debate sério e compromissado acerca da "cultura standard, simplificadora, descomplicadora, manualesca, enfim uma cultura jurídica" (STRECK, 2013, p. 205) deficiente e precária.

\section{IMPLANTAÇÃO DE CURSOS TECNÓLOGOS JURÍDICOS: UMA ALTERNATIVA À CRISE DO ENSINO JURÍDICO?}

Com o advento das modificações mercadológicas decorrentes do capitalismo $^{19}$, no início do século XX (vinte), ocorreram transformações no sistema educacional, onde "[...] novas demandas por um novo modelo de trabalhador emergiram exigindo a construção de novas modalidades no ensino profissional institucionalizado que dessem conta dos processos de reestruturação produtiva" (DUCH, 2008, p. 5), atendendo, assim, os anseios de profissionalização da sociedade brasileira.

\footnotetext{
19 Verifica-se que, nesse contexto, "em decorrência de sucessivas crises do capitalismo internacional antecedente à década de 1960, o modelo econômico agroexportador vigente no país cede espaço para que o industrialismo tomasse grande impulso, tornando-se o pólo da economia brasileira. Uma nova ordem urbano-industrial foi se implantando no país desde então" (DUCH, 2008, p. 3).
} 
Essa breve contextualização é pertinente para que se atente ao fato de que a implementação dos cursos tecnólogos foi estimulada diante da necessidade de mão-de-obra no mercado de trabalho.

Atualmente, no Brasil, em relação à educação profissional pode-se evidenciar a seguinte formatação, em três níveis: a) Formação inicial e continuada ou qualificação profissional; b) Educação profissional técnica de nível médio; c) Educação profissional tecnológica de graduação e pós-graduação, nos termos do Decreto $n^{0} 5.154 / 2004$, que prevê atualmente a educação profissional, prevista pela Lei de Diretrizes e Bases da Educação Nacional (Lei $\mathrm{n}^{\circ}$ 9.394/1996). Com isso, sinaliza-se que o objeto de estudo deste artigo se insere neste último nível, visto que analisa a educação profissional tecnológica jurídica, com status de graduação. ${ }^{20}$

Recentemente, além da existência de cursos técnicos jurídicos ${ }^{21}$, há propostas para a implantação de cursos de tecnólogos jurídicos no país, razão pela qual este debate constitui-se como uma questão de ordem à luz da crise do ensino jurídico. Diante disso, primeiramente, é fundamental ressaltar a diferenciação entre curso técnico e tecnólogo.

A grande diferença é que enquanto o curso técnico em serviços jurídicos possui natureza de ensino profissional técnico, o curso de tecnólogo jurídico possui natureza de curso superior. ${ }^{22}$

O Decreto $n^{\circ} 5.773 / 06$ - ao dispor sobre o exercício das funções de regulação, supervisão e avaliação de instituições de educação superior e cursos superiores de graduação e sequenciais no sistema federal de ensino - instituiu o Catálogo Nacional de Cursos Superiores de Tecnologia, que se caracterizou como um: " [...] guia referencial de orientação para estudantes, educadores, sistemas e instituições de ensino, entidades corporativas, empregadores e público em geral a respeito da oferta desses cursos" (MACHADO, 2010, p. 90). Ou seja,

\footnotetext{
${ }^{20}$ Razão pela qual não se adentrará, neste estudo, no mérito dos cursos a nível técnico. No Brasil, atualmente, sabe-se que existem cursos técnicos jurídicos, que visam formar profissionais para aturem no apoio administrativos das atividades jurídicas.

${ }^{21}$ Conforme pode ser verificado no catálogo nacional de cursos técnicos (BRASIL, 2016).

${ }^{22} \mathrm{O}$ que faz pressupor que, nos cursos tecnólogos, exige-se o cumprimento de algumas atividades inerentes à qualificação de ensino superior, como por exemplo: realização de estágio supervisionado e/ou elaboração um trabalho de conclusão de curso.
} 
o mencionado catálogo possui uma importância maior do que um mero fichário de denominação de cursos, visto que trata-se de um verdadeiro norteamento para manutenção e aprimoramento da qualidade do ensino profissional.

É importante que se compreenda que a implantação de cursos tecnólogos jurídicos é uma temática complexa, que merece uma análise mais aprofundada, atentando-se para a realidade jurídico-social do ensino superior no Brasil, principalmente hodiernamente, haja vista o fomento à democratização do ensino, como fora mencionado anteriormente.

O curso de tecnólogo jurídico, que tem o status de um curso superior, se propõe a formar, num período de aproximadamente ${ }^{23}$ apenas dois anos, indivíduos com uma base jurídica mínima, para serem considerados aptos a realizarem tarefas de apoio. É, sem dúvida, um discurso atrativo do ponto de vista mercadológico, num cenário atual de crise econômica, visto que há a possibilidade de conquista do diploma superior, e suposta qualificação profissional, de forma rápida.

A sensibilidade da temática é evidentemente perceptível, pois a proposta direciona-se no sentido que criar uma categoria profissional subalterna no universo jurídico, com o discurso envolvido com uma promessa de potencial mobilidade social, entretanto, sem atingir a devida função social do processo educativo.

Diante dessa conjuntura é crucial refletir qual a utilidade do ensino jurídico superior, com o objetivo de delinear os desafios para uma possível reestruturação do processo de ensino e aprendizagem.

Na concepção de Ana Carla Bliacheriene (2011), o ensino jurídico não serve meramente para "ensinar teorias jurídicas ou memorizar leis, mais sim apresentá-las como instrumentos para o desenvolvimento de valores sociais como justiça, isonomia, respeito à dignidade humana" (BLIACHERIENE, 2011, p. 150), visto que tem como escopo a construção do saber e não a mera transmissão formal de conteúdo e conhecimento técnico.

Na visão de Luis Alberto Warat (2004c; 2004; 2004b; 2004d) a função

${ }^{23}$ Alguns cursos possuem duração de até 03 (três) anos. 
do processo educativo é contribuir para a reflexão, assim, tem-se como função estimular um:

[...] discurso que piensa los problemas que surgen de la acción educativa y no una actividad dogmática que pontifica dicha acción a través de una aspiración de trascendencia y universalidad, sugiere, así una relación crítica y dialética en función a la praxis pedagógica. ${ }^{24}$ (WARAT, 2004c, p. 362).

Justamente sob estas concepções de Ana Carla Bliacheriene (2011) e Luis Alberto Warat (2004c; 2004; 2004b) que torna-se possível evidenciar a inviabilidade de implantação do ensino tecnólogo jurídico, pois tal modalidade de ensino somente fomenta a fragilidade do ensino jurídico e agrava a situação da crise educacional no Brasil.

Tendo em vista a repercussão social da implantação de cursos tecnólogos, há a necessidade de autorização do Ministério da Educação - MEC, e é importante, também que haja a manifestação das instituições representantes de classes profissionais, como por exemplo a Ordem dos Advogados do Brasil - $\mathrm{OAB}^{25}$, ligadas aos cursos técnicos e/ou tecnológicos que pretendem ser criados.

Recentemente, o Ministério da Educação - MEC autorizou o funcionamento do curso superior de tecnologia em Serviços Jurídicos, apesar de expressa manifestação contrária da Ordem dos Advogados do Brasil - OAB. ${ }^{26}$

Durante a tramitação do pedido desta mencionada autorização, a OAB manifestou-se, basicamente, sob o fundamento de que haveria a possibilidade de um conflito de competência entre o exercício das atividades advocatícias e as atividades dos futuros tecnólogos jurídicos.

Nesta toada, defende-se também que, além de extrapolar as compe-

\footnotetext{
${ }^{24}$ Tradução livre: [...] o discurso que pensa os problemas decorrentes da ação educativa e não uma atividade dogmática que pontua essa ação por uma aspiração de transcendência e universalidade, sugere, assim, uma relação crítica e dialética em função da práxis pedagógica (WARAT, 2004c, p.362).

${ }^{25}$ Infelizmente, não são raras as omissões que o MEC comete no que tange à fiscalização da qualidade do ensino jurídico no Brasil. Diante disso, torna-se mister reconhecer o louvável posicionamento institucional da Ordem dos Advogados do Brasil OAB no combate à banalização do ensino jurídico, buscando evitar a proliferação em demasia dos cursos de Direito.

${ }^{26}$ Parecer CNE/CES No: 68/2017 do Conselho Nacional de Educação.
} 
tências advocatícias, os cursos tecnólogo de serviços jurídicos colocam nitidamente em risco às demandas de estágio para os graduandos em Direito, na medida em que a função/cargos dos tecnólogos pode passar a ser mais atrativas aos setores que necessitam de estagiários, pois, muita das vezes, acabam tendo que, periodicamente em virtude da rotatividade ${ }^{27}$, contratar novos estagiários, treiná-los e adaptá-los às novas funções, e isto tudo demanda tempo e dinheiro para as instituições (públicas e privadas).

Seria mais cômodo inserir neste mercado profissionais para auxiliarem os juristas de maneira regular e perene, sem a necessidade de periódicos treinamentos? Então, a quem interessaria essa inovação educacional? São problemas muito complexos, mas que tem que ser debatidos urgentemente, tanto pela academia jurídica quanto pelos órgãos competentes.

Em âmbito acadêmico, a preocupação ainda não é tão difundida, visto que não se visualizam mobilizações institucionais nesse sentido, bem como são limitadas as produções acadêmicas com esta proposta reflexiva. Tal cenário, proporciona o surgimento dos seguintes questionamentos: Quem seriam os beneficiários deste silenciamento? Quais as razões das instituições de ensino, públicas e privadas, não criarem mobilizações de resistência à estas inovações educacionais?

No que refere ao enfrentamento dos órgãos competentes, como fora dito, o MEC parece não se preocupar efetivamente com a crise do ensino jurídico, que se agrava cada vez mais, motivo pelo qual aprova a implantação de cursos sem se debruçar sobre os riscos sociais e mercadológicos (concretos e potenciais), levantados pelas entidades representativas, como é o caso da Ordem dos Advogados do Brasil - OAB.

Nesse sentido, nota-se que a manifestação pública da Ordem dos Advogados do Brasil vem sendo em defesa do ensino jurídico, na medida em que busca evitar a criação desses cursos tecnólogos.

Por outro lado, tem-se que considerar que a principal preocupação imediata tanto do MEC quanto da $\mathrm{OAB}$ pauta-se no que pode ser considerado

${ }^{27}$ Oriunda da própria lógica da relação de estágio, nos termos do art. 11 da Lei $n^{0} 11.788 / 08$, que regulamenta a atividade de estágio. 
como uma possível reserva de mercado profissional, mas nota-se que a problemática é ainda mais complexa, visto que atinge a qualidade, a metodologia e, consequentemente, o futuro do ensino jurídico.

Com o advento de cursos de tecnólogo em serviços jurídicos, o ensino jurídico é atingido como um todo, visto que se coloca em xeque tanto a formatação dos cursos (havendo o risco de ocorrer diminuição da carga horária do ensino da graduação, para que exista competitividade de mercado, no tocante ao "público/clientela") ${ }^{28}$ quanto ao perfil dos docentes (pois estes podem ser envolvidos a adotar uma metodologia mais compatível com um ensino mais tecnólogo do que com a graduação em Direito, o que causaria uma espécie de indústria de docentes especialistas em simplificar o Direito).

Outro fator que deve ser considerado para uma possível implantação (bem como possível difusão/ampliação) de cursos tecnólogos em serviços jurídicos é a demanda de mão-de-obra. Acontece que o Brasil é um dos países que mais formam bacharéis em Direito no mundo. É evidente que no mercado jurídico brasileiro atual não há a necessidade urgente de mão-de-obra jurídica oriunda de curso de tecnólogo jurídico.

Com base nessa realidade que se instaura no Brasil atual, após todo o período de críticas ao ensino jurídico, desenvolvidas por Luis Alberto Warat (2004), pode-se verificar que:

[...] a dogmática jurídica pouco mudou. Pode-se dizer que em certa medida, ocorreu um retrocesso, em face da multiplicação das produções estandardizadas, formas de mercancia de conhecimento pret-à-portêr disponível em qualquer aeroporto, supermercado ou rodoviária do país. O saber jurídico que acaba sendo obnubilado pela informação fragmentada - hoje cabe em 140 caracteres, para usar uma imagem tipicamente contemporânea (STRECK, 2013, p. 9)

Diante disso, sustenta-se que não há a necessidade de implantação de cursos tecnólogos jurídicos no Brasil para que se possa combater a crise do

\footnotetext{
${ }^{28}$ Infelizmente, diante dessa lógica mercadológica do ensino jurídico, essa é a realidade que se insere uma análise dos impactos e/ou consequências do advento de cursos tecnólogos na área jurídica.
} 
ensino jurídico. Aliás, propõe-se que a alternativa mais adequada e sensata não seria criar cursos tecnólogos, mas sim aprimorar o ensino jurídico em vigor, estabelecimento mecanismos de controle de qualidade. ${ }^{29}$

\section{DESAFIOS A SEREM ENFRENTADOS DIANTE DA CRISE DO ENSINO JURÍDICO BRASILEIRO}

Nessa complicada atual conjuntura de crise do ensino jurídico, é crucial delinear possíveis alternativas para buscar amenizar os impactos de um declínio do ensino jurídico e, consequentemente, evitar a banalização da crise do ensino jurídico, pois "[...] una nueva jus-didáctica implica no solo la implementación de técnicas y estratégias pedagógicas más actualizadas sino también um reexamen de lo que secularmente se viene mostrando como 'fenómeno jurídico'" 30 (WARAT, 2004c, p. 362).

Repensar a função social do espaço universitário é algo necessário e deve se processar permanentemente, com o objetivo de buscar a reestruturação dos papéis desempenhados tanto pelos docentes quanto pelos discentes no processo de ensino e concretização da aprendizagem (BLIACHERIENE, 2011, p. 140-152).

Para tanto, é importante que se reconheça que a responsabilidade da atual crise do ensino jurídico é compartilhada ${ }^{31}$ entre o Estado, as Instituições de Ensino Superior - IES, os docentes e os próprios discentes, que devem almejar construir soluções efetivas para superar a crise do ensino jurídico.

Em relação ao Estado, a responsabilidade é evidente, pelo fato da

\footnotetext{
${ }^{29} \mathrm{~A}$ qualidade do ensino jurídico, bem como a utilização da metodologia na transmissão do conhecimento jurídico são temas complexos, visto que " [...] no existen recetas fijas, ni possibilidades de utilizar la misma estratégia em todos los países." (WARAT, 1972, p. 16). Tradução livre: "[...] não existem receitas fixas nem possibilidades de utilizar a mesma estratégia em todos os países" (WARAT, 1972, p. 16).

${ }^{30}$ Tradução livre: "Uma nova didática jurídica implica não somente a implementação de técnicas e estratégias pedagógicas mais atualizadas mas também um reexame do que secularmente se vem mostrando como 'fenômeno jurídico'" (WARAT, 2004c, p. 362).

31 Nesse contexto, são pertinentes as reflexões de Joseph Lowman (2004), ao tratar de questões centrais no que tange às relações de se estabelecem entre o ensinar e o aprender, pois: "Em que medida é o aprendizado função do ensino? Em que medida o ensino pode ser avaliado, tomando-se como base o que os estudantes aprendem?" (LOWMAN, 2004, p. 24).
} 
educação ser um direito social fundamental, previsto pela Constituição Federal de 1988.

No tocante às Instituições de Ensino Superior a responsabilidade relaciona-se a uma obrigação de manter o ensino jurídico pautado nas exigências dos órgãos de fiscalização e controle. Nas instituições públicas, deve-se assumir o compromisso de constantes fiscalizações da qualidade, por meio de feedback institucional do ensino e atualização dos recursos que são necessários para funcionamento do curso. Já nas instituições de ensino privadas, é necessário que ocorra, além dos compromissos inerentes às Instituições de Ensino Públicas, o compromisso de manter o ensino de qualidade sem sobrepor os valores lucrativos.

Os docentes possuem crucial parcela de contribuição nesse cenário, pois devem buscar assumir o compromisso de efetivar um ensino exemplar. Nesse sentido, nota-se a dificuldade do docente, visto que:

[...] além de um sólido domínio da matéria, o ensino universitário de qualidade parece ser uma tarefa complexa, que requer a competência de se comunicar bem com os estudantes, em grandes ou pequenos grupos, em situações formais ou informais, e relacionar-se com eles como pessoas, de maneira que eles sintam como positivas e motivadoras. O ensino universitário exemplar deve engendrar um aprendizado ativo não somente dos fatos básicos, teorias e métodos, mas também das relações entre os diferentes ramos do conhecimento. (LOWMAN, 2004, p. 22).

Por outro lado, pondera-se que a responsabilidade da crise do ensino jurídico também pode ser atribuída aos discentes tanto pelo fato de que estes buscam um ensino jurídico pautado na lógica codificadora e mecanicista tanto pelo fato de que o aprendizado é "[...] algo evidenciado por uma ampla gama de qualidades e comportamentos mensuráveis do estudante" (LOWMAN, 2004, p. 25).

Dentre os desafios que merecem ser enfrentados diante da crise do ensino jurídico destacam-se: a) A multidisciplinariedade do ensino jurídico; b) O fortalecimento da fiscalização do ensino jurídico; c) A ruptura do for- 
malismo no ensino jurídico.

\subsection{Multidisciplinaridade do ensino jurídico}

A multidisciplinariedade do Direito é praticamente inquestionável, haja vista que se trata de uma área do conhecimento que se comunica com outras áreas do saber científico.

Entretanto, nota-se que, em sua grande maioria, na prática, o ensino jurídico é pautado num isolamento acadêmico, que em nada facilita a aprendizagem, muito pelo contrário, visto que somente potencializa a cultura segregacionista que está presente no mundo acadêmico jurídico.

Assim, o conhecimento jurídico não deve ser transmitido de forma fragmentada e isolada do contexto sócio-cultural-político que vivenciam os discentes, sob o risco comprometer a qualidade do ensino, pois:

[...] a compreensão de que à aquisição de conhecimento de forma compartimentada e dissociada não representa uma forma eficaz no processo ensino/aprendizagem, quebrando assim o paradigma cartesiano da decomposição da observação do fenômeno em partes para a interpretação de uma realidade complexa que o mundo não é composto de fenômenos isolados (COLAÇO, 2006, p. 105)

Nessa linha de raciocínio, verifica-se que "[...]a supremacia do conhecimento fragmentado de acordo com as disciplinas impede frequentemente de operar o vínculo entre as partes e a totalidade" (MORIN, 2004, p.14). Deve-se, assim, buscar uma forma de aprendizagem com base na realidade contextual.

Diante disso, uma possível alternativa para a crise do ensino jurídico é a utilização da multidisciplinariedade da ciência jurídica, possibilitando a formação do discente através de concepções de variadas áreas do conhecimento, por meio de palestras/aulas com professores convidados para expor a visão e o entendimento de outra ciência e a necessidade do Direito se sensibilizar como compreender o fenômeno analisado, não puramente sob o viés legalista, mas com base em um contexto científico eclético e humanamente 
compreensível. Podendo, inclusive, haver um diálogo com a sociedade civil, atendendo os anseios sociojurídicos da comunidade localizada próxima às instituições de ensino.

Além disso, as atividades de prática de estágio extracurricular, poderiam ter a influência de outras áreas na construção do processo de aprendizagem, podendo, assim, contribuir para o afastamento da noção de que o estágio, na área jurídica, serve apenas como ensinar o discente como instrumentalizar o direito pleiteado em meras petições e/ou pareceres.

\subsection{Fortalecimento da fiscalização do ensino jurídico}

Outro desafio a ser enfrentado, à luz deste cenário de crise do ensino jurídico, é o fortalecimento da fiscalização da quantidade e qualidade do ensino jurídico fornecido pelas Instituições de Ensino Superior.

Atualmente, existe o Sistema Nacional de Avaliação da Educação Superior - SINAES ${ }^{32}$, que avalia tanto as instituições como os alunos, em relação ao ensino, à pesquisa e à extensão no curso de graduação em Direito. ${ }^{33}$

A principal forma de avaliação do ensino é, basicamente, através da análise do desempenho dos estudantes no Exame Nacional de Desempenho dos Estudantes - ENADE, que é um exame aplicado com certa periodicidade, que afere a qualidade do ensino por meio por meio do desempenho dos discentes em relação a alguns conteúdos mínimos necessários para atuação na área do conhecimento específica e, além disso, realiza um levantamento do perfil dos estudantes.

Acontece que, apesar da ciência jurídica ser muito dinâmica, realidade que exige dos profissionais uma atualização - tanto científica quanto pedagógica - constante, nota-se que não há uma fiscalização do nível de atualização

\footnotetext{
${ }^{32}$ Que foi um sistema criado pela Lei $n^{0} 10.861 / 04$, com o escopo de, nos termos de seu art. $1^{\circ}, \S 1^{\circ}$, tem "por finalidade a melhoria da qualidade da educação superior, orientação da expansão da sua oferta".

${ }^{33}$ Outros dados quantitativos podem ser evidenciados, como por exemplo: os índices de aprovações e reprovações em provas de concursos e exame da OAB. Entretanto, apesar de fornecerem percentuais analisáveis, compatíveis com a noção de crise do ensino jurídico, evidencia-se que são fatores indiretos de fiscalização, razão pela qual não fora destacado neste estudo.
} 
destes docentes, pois esta avaliação fica a critério da instituição de ensino. Por este motivo, sustenta-se que há a possibilidade de haver um exame para o corpo docente, nos termos do ENADE.

Além disso, a fiscalização dos cursos de graduação deveria ser realizada por meio de vistorias periódicas e semestrais, agendadas e, inclusive, não agendadas, para que se pudesse analisar a realidade da instituição através de relatórios elaborados com base na realidade in loco, bem como por meio de entrevistas aos discentes e corpo docente.

Tendo em vista que a fiscalização do ensino e a preocupação com a qualidade, de maneira efetiva, acabam exercidas basicamente pela $\mathrm{OAB}$, haja vista a ineficiência da atuação do MEC, acredita-se que a mobilização conjunta de outras instituições públicas, a exemplo do Ministério Público, seria crucial para o aperfeiçoamento da fiscalização e aprimoramento da qualidade do ensino jurídico.

Nessa perspectiva, é pertinente considerar a reflexão realizada por Lênio Streck Streck (2013), ao abordar o ensino jurídico por meio de uma analogia com a ciência médica, com a pretensão de refletir acerca da gravidade dessa fragilidade em que se encontra o ensino jurídico no Brasil, pois é preciso questionar se: “[...] alguém se operaria com um médico que escrevesse um livro chamado 'cirurgia cardíaca simplificada'? Ou o 'ABC da operação de cérebro'?" (STRECK, 2013, p. 20). Muito provavelmente a resposta seria negativa.É crucial questionar o porquê dessa banalização ser verificada no Direito.

Diante dessa gravidade, entende-se que o fortalecimento da fiscalização do ensino jurídico é uma necessidade não somente dentro do âmbito do universo jurídico, mas, em verdade, trata-se de uma sociedade como um todo.

\subsection{Ruptura do formalismo no ensino jurídico}

Por fim, tem-se que a ruptura do formalismo no ensino jurídico é outro desafio a ser enfrentado diante da crise. Esse formalismo no ensino se verifica de diversas formas, mas, de maneira resumida, destacam-se: a) A linguagem jurídica; b) $\mathrm{O}$ distanciamento entre professor e o aluno;

A linguagem jurídica consiste em ser um instrumento potencializa- 
dor do formalismo, pois é um tipo de linguagem que possui uma peculiaridade semântica, na medida em que se insere em um universo hermenêutico bastante próprio. Nesse sentido, é interessante observar o fenômeno da apriorização, sustentado por Pierre Bourdieu (1989):

O efeito da apriorização, que está inscrito na lógica do funcionamento do campo jurídico, revela-se com toda a clareza na língua jurídica que, combinando elementos diretamente retirados da língua comum e elementos estranhos ao seu sistema, acuso todos os sinais de uma retórica da impersonalidade e da neutralidade. (BOURDIEU,1989, p. 215).

Segundo Pierre Bourdieu (1989), o processo linguístico jurídico possibilita a construção de dois efeitos: a) Neutralização, haja vista a construção de frases impessoais e objetivas; b) Universalização, visto que exprime generalidade da regra do direito, pressupondo a existência de um consenso ético. (BOURDIEU, 1989, p.215-216).

Sendo assim, ao apresentar a ciência jurídica ao discente, tem-se que o professor possui o desafio de, ao mesmo tempo de transmitir o conhecimento jurídico, estimular a construção de uma linguagem prática acessível e democrática. Nesse contexto, a multidisciplinariedade seria um fator primordial para essa construção de uma linguagem jurídica clara, objetiva e, evidentemente, acessível.

O outro pilar do formalismo no ensino é o distanciamento entre professor e o aluno, visto que, não é muito raro, haverem salas superlotadas, o que dificulta a interação entre docente e discente.

Com isso, impõe-se de forma necessária a limitação do quantitativo de discentes por professor, para que hajam proveitosas discussões práticas em sala de aula, pois " [...] a discussão requer interação entre estudante e professor, assim, sua eficácia depende rigorosamente da qualidade das relações professor-estudante" (LOWMAN, 2004 , p. 157). Nessa perspectiva, salas de aula superlotadas, contribuem para o distanciamento entre o aluno e o professor e, consequentemente, inviabilizam um ensino jurídico crítico-reflexivo. 


\section{CONSIDERAÇÕES FINAIS}

Diante da crise do ensino jurídico, conclui-se que a implantação de cursos tecnólogos de serviços jurídicos não é uma alternativa - nem viável, nem eficaz - para que se possa combater, ou pelo menos amenizar, a banalização do curso de graduação em Direito e da crise do ensino jurídico de modo geral, visto que potencializam o risco de extrapolar competências inerentes a um curso tecnólogo e, na prática, há a possibilidade de serem atingidas as atribuições de juristas e estagiários do curso de graduação em Direito.

Além dessa preocupação mercadológica, que se faz logicamente necessária, é crucial compreender, também, que a implantação de cursos tecnólogos em serviços jurídicos em nada contribuem para a solução da crise. Aliás, pelo contrário, pois a implantação destes cursos é um instrumento potencializador da utilização de mecanismos de ensino codificador. Assim, a acriticidade estaria sendo difundida para além dos cursos de graduação e entraria para o universo dos cursos profissionalizantes, em nível tecnólogo. A grande diferença é que esse ensino mecanicista e ausente de reflexão estaria, nesse novo nicho mercadológico, legitimado pela própria estrutura de um curso profissionalizante, que é destinado à prática operacional e não à reflexão teórico-prática. É, portanto, um verdadeiro retrocesso para a educação jurídica.

Nestes termos, evidencia-se que a implantação de tais cursos configura-se como um verdadeiro agravamento da crise do ensino jurídico, tendente à banalização do senso comum teórico dos juristas (WARAT, 2004d).

Nesse cenário, com o escopo de possibilitar uma análise sobre a necessária reestruturação do processo de ensino/aprendizagem, bem como acerca da função social da ciência jurídica, propõe-se o aperfeiçoamento do atual sistema de ensino jurídico, por meio da utilização da multidisciplinariedade, do fomento à fiscalização do ensino jurídico e da ruptura do formalismo. A implementação de cursos de tecnólogos jurídicos não pode ser vista como solução pedagógica para a crise do ensino jurídico no Brasil, pois não oferece (ainda que minimamente) caminhos para a construção e fortalecimento do saber jurídico como ciência. 


\section{REFERÊNCIAS}

ALMEIDA, F; CAMARGO, S. B; SOUZA, A. L. D. Direito e Realidade: desafios para o ensino jurídico. In: FEFERBAUM, Marina; GHIRARDI, José Garcez. Ensino do direito em debate: reflexões a partir do $1^{\circ}$ Seminário Ensino Jurídico e Formação Docente. São Paulo: Direito GV, 2013. , p. 19-32.

BARRETO, A. H. L. Os bruzundangas. Porto Alegre: L\& PM, 2001.

BENTO, F. O estudo da ética profissional no curso de graduação em Direito. Revista Em Tempo, [S.1.], v. 4, mar. 2009. ISSN 1984-7858. Disponível em: <http://revista.univem.edu.br/emtempo/article/view/122>. Acesso em: 21 mar. 2018.

BITTAR, E. C. B. Curso de ética jurídica. 10 Ed. São Paulo: Saraiva, 2013.

BLIACHERIENE, A. C. Ensino jurídico superior como vetor da cidadania e dignidade humana. In: BEÇAK, R.; VELASCO, I. M. P. O Direito e o futuro da pessoa: estudos em homenagem ao professor Antônio Junqueira de Azevedo. São Paulo: Atlas, 2011. p. 140-151.

BOVE, L. A. Uma Visão Histórica do Ensino Jurídico no Brasil. Revista da Faculdade de Direito (São Bernardo do Campo), Universidade Metodista de SP, v. 3, n.3, p. 115-138, 2006 Disponível em: < https://www.metodista.br/revistas/revistas-ims/ index.php/RFD/article/view/508/506 > Acesso em mai. 2017.

BOURDIEU, P. O poder simbólico. Tradução: Fernando Tomaz. Rio de Janeiro: Bertrand Brasil S.A, 1989

BRASIL. Presidência da República. Decreto $n^{0} 5.773$ de 9 de maio de 2006. Dispõe sobre o exercício das funções de regulação, supervisão e avaliação de instituições de educação superior e cursos superiores de graduação e sequenciais no sistema federal de ensino. Diário Oficial [da] República Federativa do Brasil, Poder Executivo, Brasília, DF, 10 mai. 2006. Disponível em: < http://portal.mec.gov.br/seed/arquivos/pdf/ legislacao/decreton57731.pdf > Acesso em jun. 2017.

BRASIL. Ministério da Educação. Brasília: $3^{\mathrm{a}}$ Ed. 2016. Catálogo nacional de cursos técnicos. Disponível em: < http://portal.mec.gov.br/index.php?option=com_docman\&view=download\&alias $=41271$-cnct-3-edicao-pdf\&category_slug=maio2016-pdf\&Itemid=30192> Acesso em jun. 2017. 
BRASIL. Ministério da Educação. PARECER CNE/CES No: 68/2017 do Conselho Nacional de Educação.2017. Disponível em:< portal.mec.gov.br/index.php?option=com_docman\&view=download\&alias=62871-pces068-17-pdf\&category_slug=abril2017-pdf\&Itemid=30192> Acesso em jun. 2017.

CHAMON, M. Crise paradigmática no ensino superior: em busca do Compromisso com a produção do conhecimento e a transformação social. In: ORDEM DOS ADVOGADOS DO BRASIL. O futuro da universidade e os cursos de direito: novos caminhos para a formação profissional. Brasília, DF: OAB, Conselho Federal, 2006, p. 39-56.

COLAÇO, T. L. Aprendendo a ensinar direito o Direito. Florianópolis: OAB/SC Editora, 2006.

CONJUR. Escolas tradicionais aprovam mais no concurso do MP-SP. Consultor Jurídico, 2007. Disponivel em: <https://www.conjur.com.br/2007-ago-27/escolas_tradicionais_lideram_concurso_mp-sp>. Acesso em: 15 Mar 2018.

CONSELHO NACIONAL DE JUSTIÇA (CNJ). Censo do Poder Judiciário. 2014. Disponível em: <www.cnj.jus.br/images/imprensa/vide-censo-final.pdf> Acesso em Mar. 2018.

DUCH, M. A. B. G. Estudos da implementação de Cursos Superiores de Tecnologia. In: $1^{\circ}$ Seminário Nacional de Educação Profissional e Tecnológica, 2008, Belo Horizonte. ANAIS do $1^{\circ}$ Seminário Nacional de Educação Profissional e Tecnológica, 2008. Disponível em <http://www.senept.cefetmg.br/galerias/Arquivos_senept/anais/ quarta_tema3/QuartaTema3Artigo6.pdf> Acesso em Jun. 2017.

ECO, H. Como se faz uma tese. Trad. Gilson Cesar Cardoso de Souza. 14. ed. São Paulo: Perspectiva, 1998.

GIL, A. C. Metodologia do ensino superior. São Paulo: Atlas, 2009, p. 69.

LOWMAN, J. Dominando as técnicas de Ensino. Tradução: Harue Ohara Avritcher. São Paulo: Atlas, 2004.

MACHADO, L. R. S. Organização da educação profissional e tecnológica por eixos tecnológicos. Linhas Críticas (UnB), v. 16, n. 30, p. 89-180, 2010. Disponível em: <periodicos.unb.br/index.php/linhascriticas/article/viewFile/1458/1090> Acesso em jun. 2017. 
MORIN, E. Os sete saberes necessários à educação do futuro. São Paulo: Cortez, 2004.

NEVES, S. T. A. O ensino do direito e a matriz positivista. Revista Em Tempo, [S.1.], v. 7, n. 7, mar. 2010. ISSN 1984-7858. Disponível em: <http://revista.univem.edu.br/ emtempo/article/view/25>. Acesso em: 21 mar. 2018.

PESSOA, A. M. G. Ensino jurídico no Brasil: da implantação à reforma universitária. In: PESSOA, Flávia Moreira Guimarães (org.). Reflexões sobre a docência jurídica. Série Estudos de Metodologia. Volume 1. Aracaju: Evocati, 2013, p.21-62.

RODRIGUES, H. W. Popper e o processo de ensino-aprendizagem pela resolução de problemas. Revista Direito GV, v. 6 - 1, p. 39-57, 2010. Disponível em: <www.scielo. $\mathrm{br} / \mathrm{pdf} / \mathrm{rdgv} / \mathrm{v} 6 \mathrm{n} 1 / 03 . p d f>$ Acesso em Mar. 2018

SANCHES, R. C. F; GIMENEZ, M. Z. Doze anos de mestrado em Direito do UNIVEM: formando docentes para o BrasiL. Revista Em Tempo, [S.1.], v. 12, jan. 2014. ISSN 1984-7858. Disponível em: <http://revista.univem.edu.br/emtempo/article/ view/412>. Acesso em: 21 mar. 2018

SAVIANI, D. A expansão do ensino superior no Brasil: mudanças e continuidades. Poíesis Pedagógica, Catalão, vol. 8, n. 2, p. 4-17, 2010.

Disponível em: <https://www.revistas.ufg.br/poiesis/article/view/14035/8876>. Acesso em: 02 mai. 2017.

SILVA, E. M. T. Ensino de Direito no Brasil: perspectivas históricas gerais. Psicologia Escolar e Educacional, Campinas, v. 4, n.1, p. 307-312, 2001.

SOBOTA, K. "Don't Mention the Norm!". International Journal for the Semiotics of Law, IV/10, 1991, p. 45-60. Tradução de João Maurício Adeodato, publicada no Anuário do Mestrado da Faculdade de Direito do Recife, $n^{\circ} 7$. Recife: ed. UFPE, 1996, p. 251-273.

STRECK, L. L. Compreender direito: desvelando as obviedades do discurso jurídico. São Paulo: Revista dos Tribunais, 2013.

WARAT, L. A. La universidad latinoamericana y la eclosión pedagógica. Revista da Faculdade de Direito da UFPR,v. 15, 1972. p.15-19 Disponível em: <http://revistas. ufpr.br/direito/article/view/7204>. Acesso em: 02 Jun. 2017. 
WARAT, L. A. Epistemologia e Ensino do Direito: o Sonho Acabou. Coordenadores: Orides Mezzaroba, Arno Dal Ri Júnior, Aires José Rover, Cláudia Servilha Monteiro. Florianópolis: Fundação Boiteux, v. 2, 2004.

WARAT, L. A. Epistemologia y metodologia jurídica. In: WARAT, L. A. Epistemologia e Ensino do Direito: o Sonho Acabou. Coordenadores: Orides Mezzaroba, Arno Dal Ri Júnior, Aires José Rover, Cláudia Servilha Monteiro. Florianópolis: Fundação Boiteux, v. 2, 2004b. p. 187-192.

WARAT, L. A. Educacion y derecho. In: WARAT, L. A. Epistemologia e Ensino do Direito: o Sonho Acabou. Coordenadores: Orides Mezzaroba, Arno Dal Ri Júnior, Aires José Rover, Cláudia Servilha Monteiro. Florianópolis: Fundação Boiteux, v. 2, 2004c. p. 361-372.

WARAT, L. A. Saber crítico e senso comum teórico dos juristas. In: WARAT, L. A. Epistemologia e ensino do direito: o sonho acabou. Coordenadores: Orides Mezzaroba, Arno Dal Ri Júnior, Aires José Rover, Cláudia Servilha Monteiro. Florianópolis: Fundação Boiteux, 2004d. p. 27-35. 